\title{
Influence of Composition and Structure on Measured H Concentration in beta- Ti Alloys via Atom Probe Tomography
}

\author{
JoAnn Ballor ${ }^{1,2}$, Elizabeth Kautz ${ }^{3}$, Bharat Gwalani ${ }^{2}$, Carl Boehlert ${ }^{1}$, Arun Devaraj ${ }^{2 *}$ \\ ${ }^{1}$ Department of Chemical Engineering and Materials Science, Michigan State University, East \\ Lansing, MI \\ ${ }^{2}$ Physical and Computational Sciences Directorate, Pacific Northwest National Laboratory, \\ Richland, WA \\ ${ }^{3}$ National Security Directorate, Pacific Northwest National Laboratory, Richland, WA \\ *Corresponding author: arun.devaraj@pnnl.gov
}

Beta-Titanium (beta-Ti) alloys are used in multiple industries (e.g. aerospace, automotive, biomedical) with varying requirements for material performance [1,2]. In each of these application areas, the ingress of hydrogen $(\mathrm{H})$ and subsequent formation of hydrides and embrittlement can lead to shortened component lifetime and/or catastrophic failure [3-5]. The ability to both directly measure the concentration and distribution of $\mathrm{H}$ in $\mathrm{Ti}$ alloys and investigate the relationship between $\mathrm{H}$ and alloying elements and/or different phases is essential for an improved fundamental understanding of the $\mathrm{H}$ embrittlement process. However, direct measurement of solute $\mathrm{H}$ distribution in Ti alloys is nontrivial using transmission electron microscopy since $\mathrm{H}$ lacks an outer electron shell. Recently, efforts have been devoted to understanding how atom probe tomography (APT) can be used to quantify the $\mathrm{H}$ concentration and distribution in Ti alloys with sub-nanometer resolution [6]. APT is a uniquely powerful technique due to its high mass and spatial resolution, with equal sensitivity to all elements in the periodic table, and thus has received recent attention in the area of application of APT to H quantification.

In order to accurately quantify $\mathrm{H}$ in Ti alloys using APT, sources of spurious $\mathrm{H}$ must be identified and avoided. Ti has high affinity for $\mathrm{H}$ and can be introduced during several stages of the sample preparation process, including mechanical polishing in a water or acid based solution or focused ion beam/scanning electron microscope (FIB/SEM) lift-out procedures. While several studies have focused on quantifying the amount of $\mathrm{H}$ in different $\mathrm{Ti}$ alloy systems (e.g. Ti-Mo, Ti-Fe, Ti-6Al$4 \mathrm{~V}$ ), the effect of $\mathrm{Cr}, \mathrm{Fe}$, and $\mathrm{Al}$ additions have not previously been investigated in a systematic manner.

This work is focused on two areas of $\mathrm{H}$ quantification via APT in Ti: (1) considerations for sample preparation during the FIB/SEM lift-out process, and (2) the impact of alloying elements on measured $\mathrm{H}$ concentration. A metastable beta-phase alloy, $\mathrm{Ti}-12 \mathrm{Cr}(\mathrm{wt} \%)$, was chosen as a model system since the beta phase tends to exhibit higher $\mathrm{H}$ concentrations than other phases typically found in Ti alloys (e.g. alpha, alpha') [6].

Nominal concentrations of $1 \mathrm{wt} \% \mathrm{Fe}$ and $3 \mathrm{wt} \% \mathrm{Al}$ were added to the base $\mathrm{Ti}-12 \mathrm{Cr}(\mathrm{wt} \%)$ alloy, so that four different alloy chemistries were investigated: Ti-12Cr, Ti-12Cr-1Fe, Ti-12Cr-3Al, Ti$12 \mathrm{Cr}-1 \mathrm{Fe}-3 \mathrm{Al}$. The alloys were characterized in two conditions: a homogenized purely beta-phase condition, and after a $400^{\circ} \mathrm{C}, 12 \mathrm{hrs}$ heat treatment. $\mathrm{H}$ concentrations in beta phases from homogenized and heat treated conditions were compared, and the concentration across phase boundaries was investigated. The presence of alpha and omega phases and titanium hydrides in 
the alloy were analyzed using transmission electron microscopy (TEM). The TEM results were correlated with APT to obtain a complete understanding of phase dependent variation in $\mathrm{H}$ concentration as well as alloying element dependency on $\mathrm{H}$ concentration in individual phases.

Results indicate that sample preparation procedures impacted the measured $\mathrm{H}$ concentration in both of the above-mentioned conditions. The APT-measured $\mathrm{H}$ concentration in the two phase heat-treated samples varied depending on the phase structure and composition, see Figure 1. This work highlights the challenges and benefit of using atom probe tomography for measuring $\mathrm{H}$ in beta-Ti alloys [7].

\section{References:}

[1] S. L. Nyakana, J. C. Fanning, and R. R. Boyer, J. Mater. Eng. Perform. 14, 799 (2005).

[2] R. Kolli and A. Devaraj, Metals 8, 506 (2018).

[3] A. Alvarez, Acta Mater. 52, 4161 (2004).

[4] D. C. Rodrigues et al., J. Biomed. Mater. Res. B Appl. Biomater. 88B, 206 (2009).

[5] D. F. Teter, I. M. Robertson, and H. K. Birnbaum, 11 (n.d.).

[6] Y. Chang et al., Acta Mater. 150, 273 (2018).

[7] Acknowledgement: The work was performed at Pacific Northwest National Laboratory (PNNL), which is operated by Battelle for the United States Department of Energy (DOE). This research is funded by the Open call Laboratory Directed Research and Development (LDRD) program at PNNL. A portion of this work was performed using EMSL, a national scientific user facility sponsored by DOE's Office of Biological and Environmental Research located at PNNL.

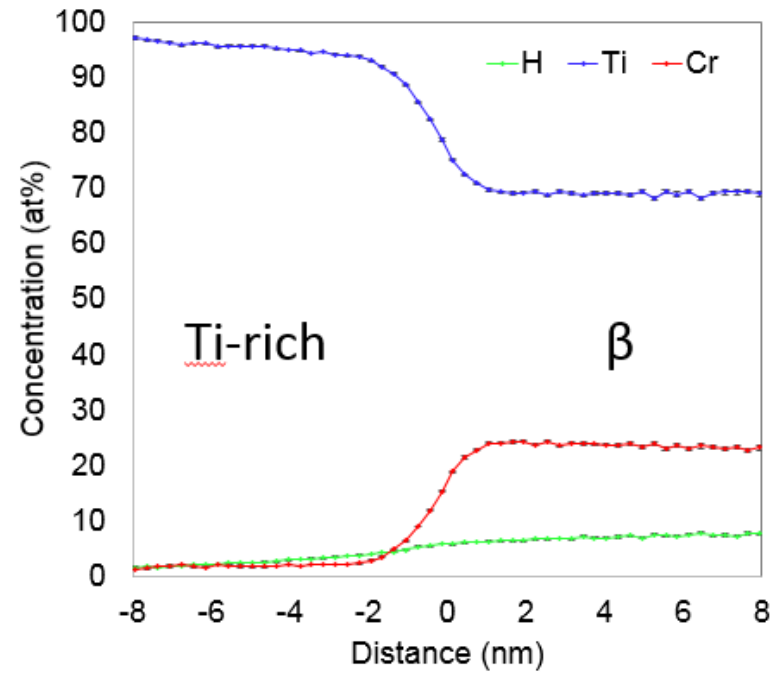

(a)

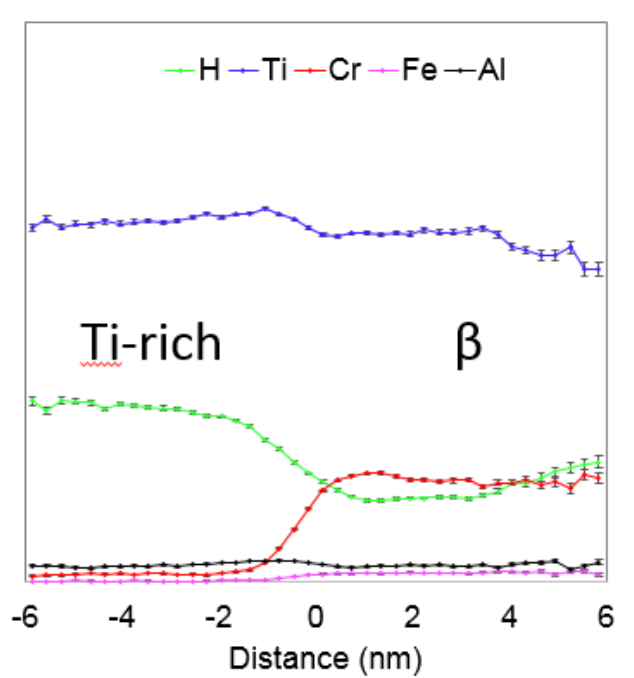

(b)

Figure 1. APT-measured $\mathrm{H}, \mathrm{Ti}, \mathrm{Cr}, \mathrm{Fe}$, and $\mathrm{Al}$ concentrations across the Ti-enriched region and Ti-depleted region boundary in (a) the heat-treated $\mathrm{Ti}-12 \mathrm{Cr}(\mathrm{wt} \%)$ alloy, where a higher $\mathrm{H}$ concentration was observed in the Ti depleted region which is the beta phase, and (b) the heattreated $\mathrm{Ti}-12 \mathrm{Cr}-1 \mathrm{Fe}-3 \mathrm{Al}(\mathrm{wt} \%)$ alloy, where a higher $\mathrm{H}$ concentration was observed in the $\mathrm{Ti}$ enriched region. The phase boundary was located at the value of 0 on the $\mathrm{x}$-axis. 